\title{
The analgesic efficacy of tramadol as a pre-emptive analgesic in pediatric appendectomy patients
}

\begin{abstract}
Preemptive analgesia is defined as administration of analgesic agents prior to surgery to prevent development of central nervous system hypersensitization thus, preventing decrease in pain threshold. The purpose of this study is to evaluate preemptive efficacy and safety of lower doses of tramadol on children undergoing appendectomy.
\end{abstract}

Methods: This study was performed in 32subjects. First group was given placebo, the second group was given tramadol $0.5 \mathrm{mg} / \mathrm{kg}$ and the third group was given tramadol $1 \mathrm{mg} / \mathrm{kg}$. Pain assessment was done using FACES Pain Scoring (FPS) for $</=6$ years of age and Visual Analog Scale (VAS) for $>6$ years of age. Heart rate and mean arterial pressure during and after anesthesia, post operative nausea and vomiting (PONV) and rescue pain medications given post surgery were recorded.

Results: The comparison of age and sex between the three groups showed that there was no significant difference noted as proven by all $\mathrm{p}$ values $>0.05$. There was a significant decrease at both heart rate and mean arterial pressure in each group of tramadol $(0.05 \mathrm{mg} / \mathrm{kg}$ and $1 \mathrm{mg} / \mathrm{kg})$ but not significant in comparing between the $0.5 \mathrm{mg}$ and $1 \mathrm{mg}$ results. There was no significant difference noted in proportion of subjects with nausea and/or vomiting as proven by all $\mathrm{p}$ values $>0.05$. There was a significant difference noted in both FPS and VAS scores between placebo and tramadol groups 15 and 30 minutes post surgery proven by all $\mathrm{p}$ values $\leq 0.05$. However, there was no significant difference noted in the FPS and VAS scores between the 2 tramadol groups as proven by $p$ values 0.37 and 0.23 respectively.

Conclusion: Tramadol at low doses has the same efficient analgesic effect that could be used as preemptive analgesia for appendectomy of children which provides good intraoperative and early post operative analgesia.

Keywords: appendectomy, analgesics, tramadol, preemptive analgesia, postoperative pain, postoperative complications
Volume 2 Issue 3 - 2015

\author{
Cheryl B Aporado, Leonny Tantri, Lilybeth \\ Tanchoco \\ Philippine Society of Anesthesiologists, Philippines
}

\begin{abstract}
Correspondence: Cheryl B Aporado, Jose R Reyes Memoria Medical Center, 2nd floor Anesthesia Office Rizal Avenue Sta, Cruz Manila, Philippines, Tel +639328791318 , Email cheryl.010583@gmail.com
\end{abstract}

Received: March 18, 20I5 | Published: May 12, 2015
Abbreviations: FPS, FACES pain scoring; VAS, visual analog scale; PONV, post operative nausea and vomiting; ANOVA, analysis of variance

\section{Introduction}

The purpose of this study is to look for efficacy, side effects and safety of low doses of tramadol as preemptive analgesia with minimal adverse effects in children undergoing appendectomy. To compare the 2 lower doses at $1 \mathrm{mg} / \mathrm{Kg} / \mathrm{dose}$ and $0.5 \mathrm{mg} / \mathrm{Kg} / \mathrm{dose}$, will give the lowest possible effective dose on pediatric population with least episodes of nausea and vomiting. Intravenous Tramadol standard dose is $1-2 \mathrm{mg} / \mathrm{Kg} / \mathrm{dose}$

Acute Appendicitis remains one of the most common causes of an abdominal emergency and becomes increasingly common throughout childhood. ${ }^{1}$ Preemptive analgesia is based on administration of an analgesic before a painful stimulus is generated, so as to prevent the subsequent development of central nervous system hyper excitability or sensitization. ${ }^{2}$

Commonly, paracetamol is used to control post operative pain on pediatrics, but its analgesic effect is often insufficient. Paracetamol is not enough for postoperative pain relief in the first eight hour postoperatively, but it can reduce postoperative opioid need and is efficient enough for pain management as morphine after the first eight hours following surgery. ${ }^{3}$ Opioids provide effective analgesia but fear of their side effects; especially respiratory depression, emesis and sedation, hence restricted their use in day-case anesthesia. ${ }^{2}$ These associated side effects may contribute to significant post operative morbidity. ${ }^{4}$

Effects of analgesics given postoperatively have been studied, but reported results were without consistent success. ${ }^{5,6}$ Strategy for pain management after surgery in children is preemptive analgesia which is defined as administration of analgesic agents prior to surgery to prevent central nervous system sensitization wherein it causes a lasting exaggerated responsiveness associated with decrease in pain threshold. ${ }^{7,8}$ Hence, it's considered that it's possible to prevent or decrease postoperative pain by giving analgesic medicine prior to surgery. ${ }^{9,10}$

Tramadol offers a central acting analgesic through opiate receptors, which produces opiate like analgesia however; it has significantly less respiratory depression effects. ${ }^{11,12}$ Tramadol was well tolerated and an effective analgesic similar to other opioids. ${ }^{13}$ The most common adverse events are nausea, vomiting, dizziness, headache, sedation, drowsiness, sweating and dry mouth. ${ }^{14}$ Although several studies have documented analgesic efficacy of tramadol, there is no local study documented about its preemptive use in appendectomy in children. 


\section{Methods}

With approval of Institutional regulatory board committee, this study was planned as a double-blinded trial. The effects of two dose levels of tramadol $(0.5$ and $1 \mathrm{mg} / \mathrm{Kg})$ at the induction of anesthesia on intraoperative and postoperative analgesia were evaluated on 32children. (M:15 F:17; age range: 3-15years of age) undergoing appendectomy. All children included in this study were in ASA physical status I or II for emergency appendectomy.

\section{Anesthesia Technique, study group and injection of tramadol}

All patients within $3 y / 0$ to $15 y$ ears of age, who were diagnosed preoperatively of acute appendicitis and will undergo open appendectomy wherein 4 surgeons were involved, were asked for consent/assent to be enrolled in the study. Informed and written consent of each patient were obtained. All subjects were given ranitidine $1 \mathrm{mg} /$ $\mathrm{kg}$ IV prior to induction. Multi parameter monitor (NIBP, SP02, heart rate) were attached to the patient. Baseline vital signs were noted and monitored up to post operative stay in the PACU.

General Anesthesia was preferred in all patients under rapid sequence induction. All subjects were given preoxygenation at 5-81pm via face mask using fentanyl, midazolam, propofol, succinylcholine or rocuronium for asthmatic patients. After the induction of anesthesia, but before intratracheal intubation, one of these 3 intravenous solutions ( $\mathrm{P}, \mathrm{T} 1$, and $\mathrm{T} 2$ ) was slowly given by the author of this study according to a randomized, double-blinded and placebo controlled protocol using fishbowl method. The solutions were prepared by the secondary researcher within three $10 \mathrm{ml}$ syringes, so that $\mathrm{P}, \mathrm{T} 1$, and $\mathrm{T} 2$ syringes contained $10 \mathrm{ml}$ serum physiologic as placebo.

The syringes were coded label to maintain the double-blind nature of the study. 9children in group P received 10cc PNSS, 13children in group T1 received $0.5 \mathrm{mg} / \mathrm{kg}$ tramadol added with PNSS to become a $10 \mathrm{cc}$ solution, 10children in group T2 received $1 \mathrm{mg} / \mathrm{kg}$ tramadol added with PNSS to become a 10cc solution; Injection of these were done within atleast 3 minutes as advocated by Radbruch et al. ${ }^{15}$ Procedure will be maintained by Isoflurane+Oxygen until the end of surgery. At the end of surgery, all anesthetics were discontinued and extubation was performed when spontaneous breathing was adequate. Post operative breakdown of cases revealed 3 of these cases were perforated and 29 cases were simple acute appendicitis. Patients were discharged from the postanesthesia care unit after a minimal 1hour observation after assuring of good pain control (Vas $<3 / \mathrm{FPS}<2$ ).

\section{Assessment of pain}

Upon arrival at the PACU as 0 , and at $15^{\text {th }}, 30^{\text {th }}$ and $60^{\text {th }}$ minute, the main anesthesiologist, who was unaware of group assignment assessed pain of each child. The assessment was done by using FPS in children at or younger than 6years old according to the modification of Ho et al. ${ }^{5}$ it was performed using 0-10 VAS in children older than 7years of age. FPS has series of 6 faces showing an increase in discomfort and/ or unhappiness, the observer selected one of these facial appearances for each case.

In 0-10 VAS that consisted of a horizontal line $100 \mathrm{~mm}$ in length, there will be a $10 \mathrm{~cm}$ baseline with 0 or no pain and 10 corresponding to worst imaginable pain writings on each side of the scale. In children that presented a FPS of 3 or higher or VAS score 5 or higher, which are considered non tolerable pain, intravenous paracetamol of $20 \mathrm{mg} / \mathrm{kg}$ was administered for relief of pain anytime within and after the first hour post surgery because following this child without doing anything will be unethical.

\section{Other parameters}

In this study, changes in hemodynamic parameters including the heart rate, mean arterial pressure were recorded for each child. Furthermore, side effects occurrences of postoperative nausea and vomiting were noted. Hemodynamic parameters were monitored. The baseline records of heart rate and mean arterial pressure before and following induction, prior to administration of the study solutions and follow-up recordings at every 15 minutes during operation and in the PACU were taken for statistical analysis between the groups.

\section{Analysis of data}

Data were encoded and tallied in SPSS version 10 for windows. Descriptive statistics were generated for all variables. For nominal data frequencies and percentages were computed. For numerical data, mean \pm SD were generated. Analysis of the different variables was done using the following test statistics:

i. ANOVA - used to compare more than two groups with numerical data

ii. Kruskal Wallis test-a non-parametric equivalent of ANOVA

iii. Repeated Measures ANOVA-used to compare more than two dependent numerical data

iv. Bonferroni test-used for pair wise comparison after a significant results in ANOVA

v. Chi-square test-used to compare/associate nominal (categorical) data.

Analysis of variance (ANOVA) was performed to detect changes over time in hemodynamic variables of heart rate and mean arterial pressure between the three groups. When statistically significant changes will be found by ANOVA, Turkey-Kramer test adjusted paired t-test was performed. Differences between groups were analyzed by unpaired Student's t-test.

For comparison of pain scores (FPS and VAS) between the study groups, the Kruskall-Wallis (between the three groups), and $\mathrm{X}^{2}$ (between placebo and tramadol groups) tests were used. Results were expressed as means +/- S.D., and statistical results were considered significant when the P-value found in each test will be lower than 0.05 .

\section{Sample size computation}

The computed number of samples was 20 per group but the study was not able to achieve this number. However, post hoc power computation showed that the present study was able to achieve at least $80 \%$ power when the outcome VAS following induction was considered with $95 \%$ confidence level.

$$
n=\left[\frac{\left(Z_{(\alpha+\beta)}\right)^{2}(S D)^{2}}{e^{2}}\right] x^{2}
$$

Where:

$\mathrm{n}=\mathrm{is}$ the number of subjects needed per group/arm 
$\mathrm{SD}=$ estimated $\mathrm{SD}$ based on the variable of main interest (vas 30 mins post $\mathrm{sx})=0.78$

$\mathrm{Z} \alpha=95 \%$ confidence level $=1.96$

$\mathrm{Z} \beta=80 \%$ power of the study $=1.28$

$\mathrm{e}=$ measure of effect (difference in vas bet tramadol low dose and placebo $)=4.80-1.89=2.91$

\section{Results}

A total of 32 subjects were included in the study. $1^{\text {st }}$ group was given placebo, the $2^{\text {nd }}$ group was given tramadol 0.5 and the $3^{\text {rd }}$ group was tramadol 1 . Table 1 shows the comparison of age and sex between the 3 groups which revealed a non significant difference on age and sex. Table 2 shows comparison of heart rate at different intervals between the 3 groups wherein results showed that there was no significant difference noted in the heart rate before induction, following induction, before giving the solution and after giving the solution. Table 3 shows the comparison of MAP at different intervals between the 3 groups wherein the results showed that there was a significant difference noted in the MAP before induction, following induction, before giving the solution and after giving the solution. Table 4 shows the pair wise comparison of MAP at different intervals between the 3 groups wherein the results revealed a significant difference between the placebo and tramadol groups before induction, following induction, before giving the solution and after giving the solution. Table 5 shows the comparison of nausea and vomiting at different intervals between the 3 groups wherein results revealed that there was no significant difference noted in proportion of subjects with nausea and/or vomiting 15 minutes, 30 minutes, 45 minutes and 60 minutes post surgery. Table 6 shows the comparison of VAS at different intervals between the 3 groups wherein results showed that there was a significant difference noted in the VAS between placebo and tramadol groups 15 and 30minutes post surgery. However, there was no significant difference noted in the VAS between the 2 tramadol groups. Table 7 shows the comparison of FPS at different intervals between the 3 groups wherein the results showed that there was a significant difference noted in the FPS between placebo and tramadol groups 15 and 30minutes post surgery. However, there was no significant difference noted in the FPS between the 2 tramadol groups.

Table I The results showed no significant difference on age and sex

\begin{tabular}{|c|c|c|c|c|}
\hline \multirow{2}{*}{ Intervals } & \multicolumn{3}{|l|}{ Groups } & \multirow{2}{*}{ p-value* } \\
\hline & $\operatorname{Placebo}(n=9)$ & Tramadol $0.5(n=14)$ & Tramadol 1 $(n=10)$ & \\
\hline \multicolumn{5}{|c|}{ Age (in years) } \\
\hline Mean \pm SD & $8.33 \pm 2.69$ & $7.79 \pm 2.58$ & $7.50 \pm 2.37$ & $0.77(\mathrm{NS})$ \\
\hline \multicolumn{5}{|l|}{ Sex } \\
\hline Female & $3(33.3 \%)$ & $7(50.0 \%)$ & $6(60.0 \%)$ & \multirow{2}{*}{$0.50(\mathrm{NS})$} \\
\hline Male & $6(66.7 \%)$ & $7(50.0 \%)$ & $4(40.0 \%)$ & \\
\hline
\end{tabular}

Comparison of age and sex between the three groups.

*p-values $>0.05$-Not significant; $p$-values $\leq 0.05$-Significant

Table 2 The results showed that there was no significant difference noted in the HR before induction, following induction, before giving the solution and following giving the solution by all $p$ values $>0.05$

\begin{tabular}{|c|c|c|c|c|}
\hline \multirow{2}{*}{ Intervals } & \multicolumn{3}{|l|}{ Groups } & \multirow[t]{2}{*}{ p-value* } \\
\hline & Placebo(n=9) & Tramadol $0.5(n=14)$ & Tramadol 1(n=10) & \\
\hline Before Induction & $107.89 \pm 8.98$ & $107.77 \pm 9.37$ & $109.00 \pm 9.70$ & 0.94 (NS) \\
\hline Following Induction & $98.67 \pm 9.31$ & $99.92 \pm 8.53$ & $102.60 \pm 9.83$ & 0.63 (NS) \\
\hline Before giving the solution & $100.56 \pm 8.78$ & $98.77 \pm 9.43$ & $101.00 \pm 10.46$ & $0.84(\mathrm{NS})$ \\
\hline Following giving the solution & $99.67 \pm 7.87$ & $94.77 \pm 8.43$ & $98.70 \pm 10.98$ & $0.50(\mathrm{NS})$ \\
\hline *p-value & $<0.0001(\mathrm{~S})$ & $<0.0001(\mathrm{~S})$ & $<0.0001(\mathrm{~S})$ & \\
\hline
\end{tabular}

Comparison of HR at different intervals between the three groups. Values are Mean \pm SD.

*p-values $>0.05$ - Not significant; $\mathrm{p}$-values $\leq 0.05$-Significant 
Table 3 The results showed that there was a significant difference noted in the MAP before induction, following induction, before giving the solution and following giving the solution as by all $p$ values $\leq 0.05$.

\begin{tabular}{llll}
\hline \multirow{2}{*}{$\begin{array}{l}\text { Intervals } \\
\text { Groups }\end{array}$} & & \multicolumn{1}{c}{ p-value* } \\
\cline { 2 - 3 } Before Induction & Placebo(n=9) & Tramadol 0.5(n=14) & $81.80 \pm 5.26$ \\
Following Induction & $75.44 \pm 5.00$ & $80.08 \pm 5.85$ & $78.40 \pm 4.99$ \\
Before giving the solution & $69.89 \pm 5.44$ & $76.00 \pm 5.85$ & $77.30 \pm 5.23$ \\
Following giving the solution & $70.67 \pm 5.87$ & $74.85 \pm 5.48$ & $0.006(\mathrm{~S})$ \\
*p-value & $69.22 \pm 4.12$ & $71.23 \pm 5.70$ & $75.20 \pm 5.55$ \\
\hline
\end{tabular}

Comparison of MAP at different intervals between the three groups. Values are Mean \pm SD.

*p-values $>0.05$ - Not significant; $\mathrm{p}$-values $\leq 0.05$-Significant

Table 4 The results revealed a significant difference between the placebo and tramadol groups following induction, before giving the solution and following giving the solution. There was no significant difference between the two groups of tramadol

\begin{tabular}{llll}
\hline & $\begin{array}{l}\text { Placebo } \\
\text { Vs } \\
\text { tramadol 0.5 }\end{array}$ & $\begin{array}{l}\text { Placebo } \\
\text { Vs } \\
\text { tramadol 1 }\end{array}$ & $\begin{array}{l}\text { Tramadol 0.5 } \\
\text { Vs }\end{array}$ \\
\hline tramadol 1 \\
\hline Before Induction & $0.18(\mathrm{NS})$ & $0.05(\mathrm{~S})$ & $1.00(\mathrm{NS})$ \\
Following Induction & $0.04(\mathrm{~S})$ & $0.006(\mathrm{~S})$ & $0.92(\mathrm{NS})$ \\
Before giving the solution & $0.27(\mathrm{NS})$ & $0.04(\mathrm{~S})$ & $0.90(\mathrm{NS})$ \\
Following giving the solution & $1.00(\mathrm{NS})$ & $0.05(\mathrm{~S})$ & $0.25(\mathrm{NS})$ \\
\hline
\end{tabular}

Pair wise comparison of MAP at different intervals between the three groups.

*p-values $>0.05$-Not significant; $\mathrm{p}$-values $\leq 0.05$-Significant

Table 5 The results showed that there was no significant difference noted in proportion of subjects with nausea and/or vomiting 15 minutes, 30 minutes, 45 minutes and 60 minutes post surgery by all $p$ values $>0.05$.

\begin{tabular}{lllll}
\hline \multirow{2}{*}{ Nausea \& Vomiting } & Groups & \multicolumn{2}{c}{ p-value* } \\
\cline { 2 - 4 } & Placebo(n=9) & Tramadol 0.5(n=14) & Tramadol 1 $(\mathrm{n}=10)$ & $0.86(\mathrm{NS})$ \\
\hline 15mins post sx & 1 & 2 & 2 & $0.40(\mathrm{NS})$ \\
30mins post sx & 3 & 2 & 1 & $0.48(\mathrm{NS})$ \\
45mins post sx & 1 & 0 & 1 & $1.00(\mathrm{NS})$ \\
60 mins post sx & 0 & 0 & 0 & \\
\hline
\end{tabular}

Comparison of nausea and vomiting at different intervals between the three groups.

*p-values>0.05- Not significant; $p$-values $\leq 0.05$-Significant

Table 6 The results showed that there was a significant difference noted in the VAS between placebo and tramadol groups I5 and 30 minutes post surgery. However, there was no significant difference noted in the VAS between the 2tramadol groups.=

\begin{tabular}{|c|c|c|c|}
\hline & $\begin{array}{l}\text { Placebo } \\
\text { Vs } \\
\text { Tramadol } 0.5\end{array}$ & $\begin{array}{l}\text { Placebo } \\
\text { Vs } \\
\text { Tramadol 1 }\end{array}$ & $\begin{array}{l}\text { Tramadol } 0.5 \\
\text { Vs } \\
\text { Tramadol } 1\end{array}$ \\
\hline 15 mins post sx & $<0.0001(\mathrm{~S})$ & $<0.0001(\mathrm{~S})$ & $1.00(\mathrm{NS})$ \\
\hline 30mins post $\mathrm{sx}$ & $<0.0001(\mathrm{~S})$ & $<0.0001(\mathrm{~S})$ & $1.00(\mathrm{NS})$ \\
\hline 45 mins post $s x$ & $0.50(\mathrm{NS})$ & $1.00(\mathrm{NS})$ & $1.00(\mathrm{NS})$ \\
\hline 60 mins post $\mathrm{sx}$ & $0.32(\mathrm{NS})$ & $0.52(\mathrm{NS})$ & $1.00(\mathrm{NS})$ \\
\hline
\end{tabular}

Pair wise comparison of VAS at different intervals between the three groups.

* p-values $>0.05$ - Not significant; $p$-values $\leq 0.05$-Significant 
Table 7 The results showed that there was a significant difference noted in the FPS between placebo and tramadol groups 15 and 30 minutes post surgery. However, there was no significant difference noted in the FPS between the 2tramadol groups

\begin{tabular}{lllll}
\hline \multirow{2}{*}{ Intervals } & Groups & & & \\
\cline { 2 - 4 } & Placebo $(\mathrm{n}=4)$ & Tramadol $\mathbf{0 . 5}(\mathrm{n}=5)$ & Tramadol 1(n=5) & p-value* \\
\hline 15mins post sx & $2.75 \pm 0.96$ & $1.60 \pm 0.55$ & $1.20 \pm 0.45$ & $0.01(\mathrm{~S})$ \\
30mins post sx & $3.25 \pm 0.50$ & $2.20 \pm 0.45$ & $1.60 \pm 0.55$ & $0.001(\mathrm{~S})$ \\
45mins post sx & $2.00 \pm 0.82$ & $2.20 \pm 0.45$ & $1.80 \pm 0.45$ & $0.56(\mathrm{NS})$ \\
60mins post sx & $1.50 \pm 0.58$ & $2.20 \pm 0.45$ & $2.20 \pm 0.84$ & 0.24 (NS) \\
\hline
\end{tabular}

Comparison of FACES pain scoring scale at different intervals between the three groups. Values are Mean \pm SD

*p-values $>0.05$ - Not significant; $\mathrm{p}$-values $\leq 0.05$-Significan

\section{Discussion}

It was demonstrated in this study that tramadol administration via intravenous route at low doses during the induction of anesthesia provided both intra operative and early post operative analgesic in children undergoing appendectomy. This presented a similar data on children undergoing inguinal surgery which was given tramadol at $1 \mathrm{mg}$ and $2 \mathrm{mg} / \mathrm{kg}$ before the beginning of surgery which reported that in the first 2hours, the intensity of pain was lower. Although FPS and VAS Scores were not different at the end of first hour, was obviously lower in tramadol group. Data in this study presented that low dose tramadol $(0.5 \mathrm{mg}$ and $1 \mathrm{mg} / \mathrm{kg})$ was a satisfactory agent in this respect, because Mean Arterial Pressure and Heart Rate intra operatively were found to be lower in children who were given tramadol during induction of anesthesia than dose given with placebo.

Vander Berg et al. ${ }^{16}$ however reported that pethidine and nalbuphine has greater effect than tramadol hence we can only say that lower doses of tramadol were better than placebo for intra operative analgesia. also found that there was an increase incidence of post operative nausea and vomiting (PONV) on tramadol compared to placebo group but in this study, there was no significant difference between the tramadol and placebo groups.

Reasons maybe because we slowly injected tramadol in 5 minutes or more since Radbruch et al. ${ }^{15}$ reported that incidence of PONV increased when tramadol was injected in $<2$ minutes. This could be because a small sample size was collected and also, we consider this because we used lower doses of tramadol on this study. Post operative respiratory depression was not seen in this study, but we can't conclude that because sample size of our study groups could not be large to evaluate this side effect.

\section{Conclusion}

We can use low doses of tramadol $(0.5 \mathrm{mg} / \mathrm{kg})$ to provide good intra operative analgesia as supplementation and less postoperative pain during the first 30-60minutes on pediatric appendectomy. Therefore, during the induction of anesthesia, tramadol maybe of choice to improve post operative quality of life of children undergoing appendectomy to provide a painless awakening from anesthesia. Although, additional pain medications maybe needed after the first hour.

\section{Acknowledgements}

None.

\section{Conflict of interest}

The author declares no conflict of interest.

\section{References}

1. Telburd GL, Wallace JR, Surgery of the alimentary tact. 154: 2141 .

2. Woolf CJ. Recent advances in the pathophysiology of acute pain. $\mathrm{Br} \mathrm{J}$ Anaesth. 1989;63(2):139-146.

3. Alimian M, Pournajafian A, Kholdebarin A, et al. Analgesic effects of paracetamol and morphine after elective laparotomy surgeries. Anesth Pain Med. 2014;4(2):e12912.

4. Anderson B, Kanagasundurom S, Woollard G. Analgesic efficacy of paracetamol in children using tonsillectomy as a pain model. Anaesth Intensive Care. 1996;24(6):669-673.

5. Ho JW, Khambatta HJ, Pang LM, et al. Preemptive analgesia in children. Does it exist? Reg Anesth. 1997;122(2):125-130.

6. Van den Berg AA, Honjol NM, et al. Analgesics and ENT surgery. A clinical comparison of the intraoperative, recovery and postoperative effects of buprenorphine, diclofenac, fentanyl, morphine, nalbuphine, pethidine and placebo given intravenously with induction of anaesthesia. Br J Clin Pharmacol. 1994;38(6):533-543.

7. Van den Berg AA, Montoya-Pelaez LF, Halliday EM, et al. Analgesia for adenotonsillectomy in children and young adults: a comparison of tramadol, pethidine and nalbuphine. Eur J Anaesthesiol. 1999;16(3):186194.

8. Katz J, Kavanagh BP, Sandler AN, et al. Preemptive analgesia: clinical evidence of neuroplasticity contributing to postoperative pain. Anaesthesiology. 1992;77(3):439-446.

9. Dayer P, Collart L, Desmeules J. The pharmacology of tramadol. Drugs. 19941;47(Suppl 1):3-7.

10. Lehmann KA. Tramadol for the management of acute pain. Drugs. 1994;47(Suppl 1):19-32.

11. Schaffer J, Piepenbrock S, Kretz F-J, et al. Nalbuphine and Tramadol for the control of post operative pain in children. Anaesthesist. 1986;35(7):408-413. 
12. Scott LJ, Perry CM. Tramadol: a review of its use in perioperative pain. Drugs. 2000;60(1):139-176.

13. Ozköse Z, Akçabay M, Kemaloğlu YK, et al. Relief of posttonsillectomy pain with low-dose tramadol given at induction of anesthesia in children. Int J Pediatr Otorhinolaryngol. 2000;53(3):207-214.

14. Rose JB, Finkel JC, Aguedas Mohs A, et al. Oral tramadol for the treatment of pain of 7-30days duration in children. Anesth Analg. 2003;96(1):78-81.
15. Radbruch L, Grond S, Lehmann KA. A risk benefit assessment of tramadol in the management of pain. Drug Saf. 1996;15(1):8-29.

16. Van den Berg AA, Halliday E, Lule EK, et al. The effects of tramadol on postoperative nausea, vomiting and headache after ENT surgery. A placebo-controlled comparison with equipotent doses of nalbuphine and pethidine. Acta anaesthesiol Scand. 1999;43(1):28-33. 